\title{
A Compact 1:4 Lossless T-Junction Power Divider Using Open Complementary Split Ring Resonator
}

\author{
Kanaparthi V. PHANI KUMAR, S. S. KARTHIKEYAN \\ Dept. of Electronic Engineering, Indian Inst. of Information Technology Design and Manufacturing Kancheepuram, \\ Chennai, India 600127
}

edm13d001@iiitdm.ac.in, ssk@iiitdm.ac.in

\begin{abstract}
This paper presents the size miniaturized and harmonic suppressed lossless 1:4 T-junction unequal power divider using an open complementary split ring resonator (OCSRR). By embedding the OCSRR structure in the microstrip transmission line, slow wave effect is introduced and thereby size reduction is achieved. The dimensions of OCSRR are optimized to reduce the length of high impedance and low impedance quarter-wavelength transmission lines. In our design high impedance line length is reduced to $58.6 \%$, and low impedance line length is reduced to $12 \%$ when compared to the conventional quarter wave length lines. The proposed power divider is having small dimensions of $0.18 \lambda_{g} \times 0.33 \lambda_{g}$ and is $51.94 \%$ smaller than the conventional unequal power divider.
\end{abstract}

\section{Keywords}

Open complementary split ring resonator (OCSRR), power divider, size miniaturization

\section{Introduction}

Power divider is a passive device which is widely used in microwave and millimeter wave systems, such as feeding network for an antenna array, power amplifiers, mixers and it is also used in testing instruments to measure different characteristics of a signal. The drawbacks of conventional power divider are its larger size and the high characteristic impedance involved, when a power-dividing ratio of larger than two is required. To overcome the fabrication difficulties due to high impedance lines and to achieve size miniaturization, different techniques have been employed [1-13]. Defected Ground Structures (DGS), Photonic Band Gap structures (PBG) and Electromagnetic Band Gap structures (EBG) are used to design miniaturized microwave devices like power dividers and ring hybrid [1-6]. The slow wave effect offered by these structures is used to achieve size reduction. In [5], Wilkinson power divider using EBG cell for the suppression of harmonics and size reduction is presented. The high characteristic impedance transmission line of a $6: 1$ Wilkinson power divider is realized by embedding the EBG structure and considerable increase in the width of the narrow line is reported in [6]. A metamaterial T-junction power divider using microstrip gaps and via holes is discussed in [7]. Sub wavelength resonators like split ring resonator (SRR) and complementary split ring resonator (CSRR) are also used for design of size miniaturized and performance improved microwave devices like filters [8-10] and power dividers [11], [12].

In this paper a 1:4 lossless $\mathrm{T}$-junction power divider is designed using a subwave length resonator called open complementary split ring resonator (OCSRR). The high and low impedance lines of 1:4 unequal power divider are realized by embedding the OCSRR structure in the $50 \Omega$ microstrip line. The proposed divider is compact in size and provides better third harmonic suppression.

\section{Open Complementary Split Ring Resonator}

OCSRR is a counter part of open split ring resonator (OSRR). It was first proposed by some of the authors in CPW technology [13] and mostly used in size miniaturization and performance enhancement of microwave devices [13-16]. The layout of OCSRR and its equivalent circuit is shown in Fig. 1.

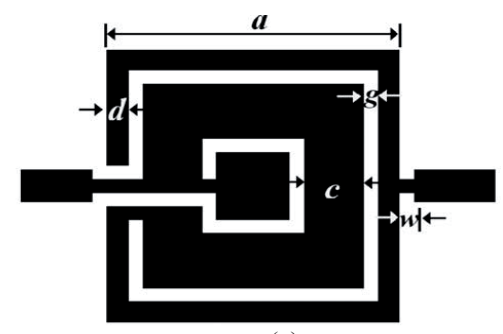

(a)

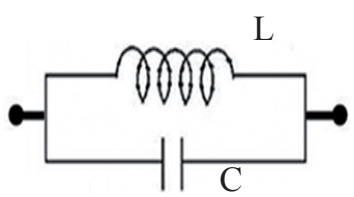

(b)

Fig. 1. (a) Layout of an open complementary split ring resonator. (b) The equivalent circuit model of OCSRR. 
When the OCSRR is excited by an axial time varying electric field, it exhibits stop band near its resonance frequency. The resonance frequency of OCSRR is given by

$$
f=\frac{1}{2 \pi \sqrt{L C}}
$$

where $L$ and $C$ are the inductance and capacitance of the open complementary split ring resonator. The OCSRR is designed and embedded in the microstrip line on FR4 substrate having dielectric constant $\varepsilon_{\mathrm{r}}=4.4$ and substrate thickness of $1.6 \mathrm{~mm}$. Simulations are carried out using full wave simulator Ansys HFSS. The frequency response of OCSRR is shown in Fig. 2, for dimensions as follows: $a=6.5 \mathrm{~mm}$, $c=1.5 \mathrm{~mm}, d=0.4 \mathrm{~mm}, g=0.5 \mathrm{~mm}$ and $w=0.4 \mathrm{~mm}$. During resonance, the OCSRR acts as an open resonator and the total transmitted energy is reflected back to source causing an attenuation pole at $f=2.72 \mathrm{GHz}$ with a maximum rejection of $26.52 \mathrm{~dB}$. Figure 3 shows the current distribution of OCSRR at resonant frequency.

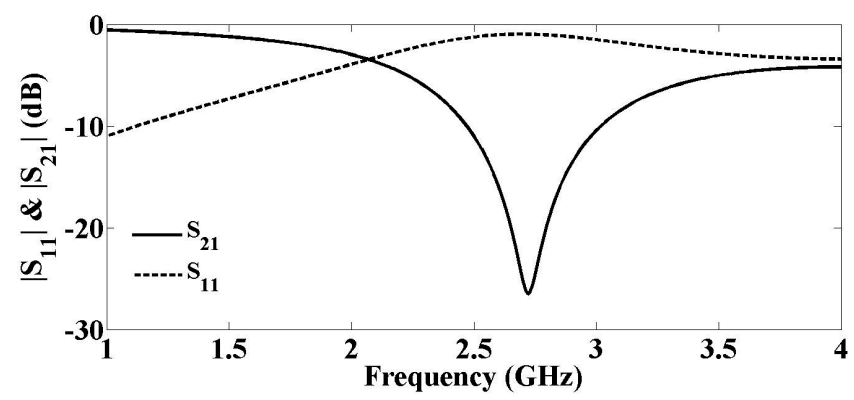

Fig. 2. Simulated scattering parameters of OCSRR.

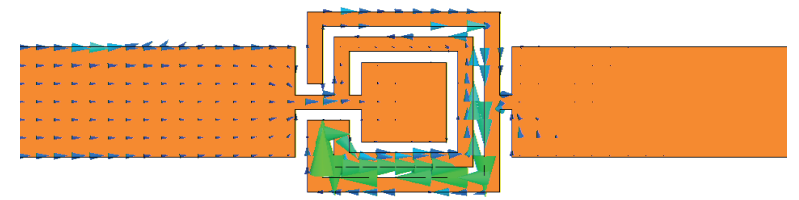

Fig. 3. Current distribution of OCSRR at resonant frequency.

\section{Transmission Characteristics of OCSRR}

To study the change in resonant frequency with respect to the dimensions of OCSRR, the parametric study of OCSRR has been done. The transmission characteristics of OCSRR are obtained by varying any one parameter and keeping all other parameters unchanged. The parameter $a$ which represents the length and also width of outer ring is varied from $5.5 \mathrm{~mm}$ to $6.5 \mathrm{~mm}$ in steps of $0.5 \mathrm{~mm}$ by keeping other parameters unchanged and simulated to obtain the transmission characteristics. The simulation result is shown in Fig. 4.

It is observed that as $a$ increases the resonant frequency decreases, this is due to an increment in parameter $a$ that increases the inductance of the OCSRR. From (1) the resonant frequency and inductance are inversely related, so as inductance increases resonant frequency decreases. The

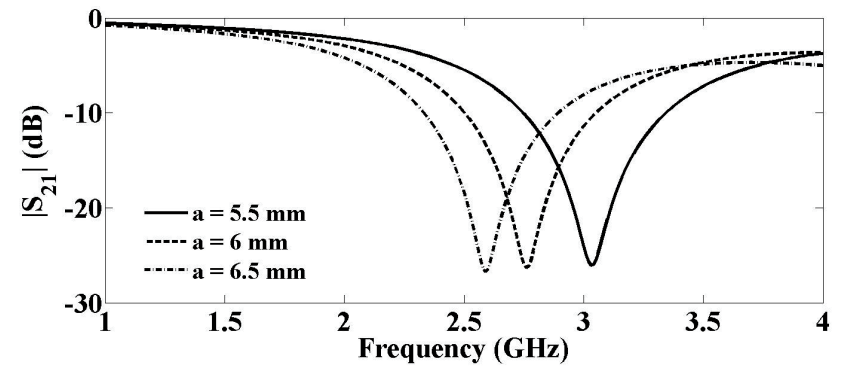

Fig. 4. Simulated frequency responses for different length $a$ of OCSRR.

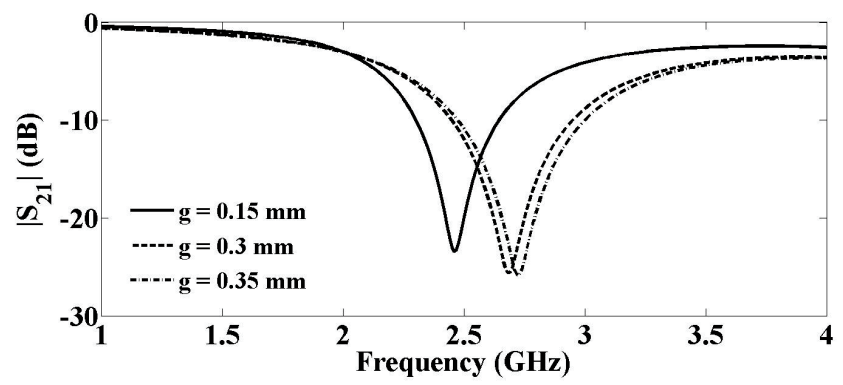

Fig. 5. Simulated frequency responses for different length $g$ of OCSRR.

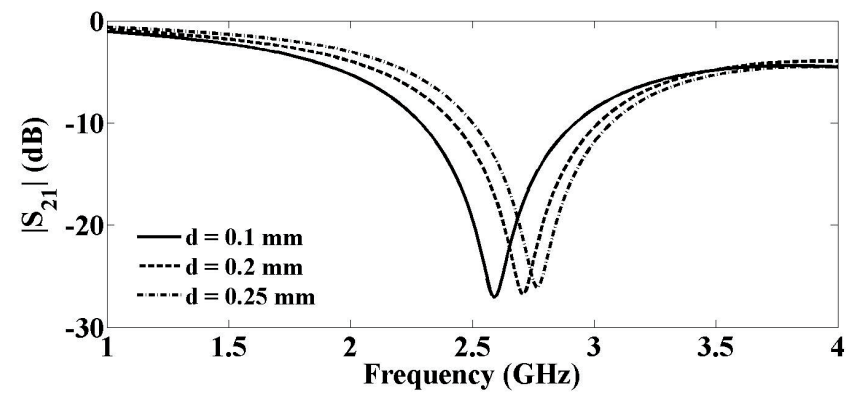

Fig. 6. Simulated frequency responses for different length $d$ of OCSRR

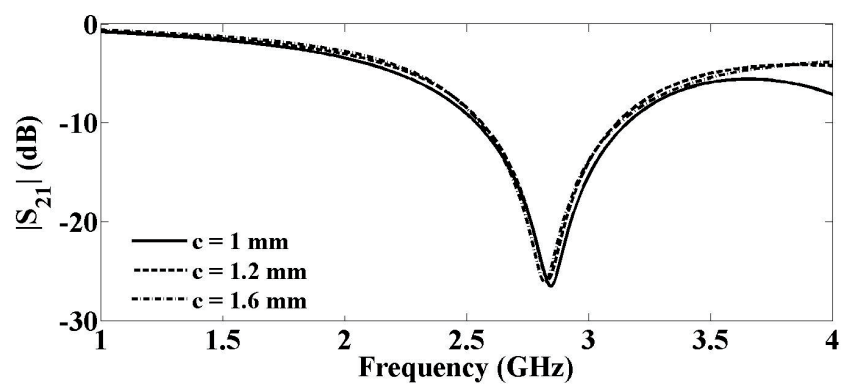

Fig. 7. Simulated frequency responses for different length $c$ of OCSRR.

gap between the rings $g$ is varied by keeping remaining parameters unchanged. As the gap is increasing the resonant frequency is increasing, this is due to increase in gap that decreases the capacitance. As the capacitance and resonant frequency are inversely related, decrease in capacitance increases the resonant frequency. Figure 5 shows the simulation results for varying the gap $g$. Similarly the other parameters $d$ and $c$ are varied and frequency response is observed. The resonant frequency is slightly increased with increase in these parameters. Fig. 6 and 7 show the simulation results for varying the parameters $d$ and $c$. 


\section{Slow Wave Factor of OCSRR}

Since OCSRR is embedded in the microstrip line it will increase the line inductance and capacitance, which in turn introduces the slow wave effect. The slow wave effect of microstrip line with and without OCSRR is calculated using (2) given in [17]

$$
S W F=\frac{\lambda_{0} \Delta_{0}}{360 L_{p}}+\sqrt{\varepsilon_{\text {eff }}}
$$

where $L_{\mathrm{p}}$ is the physical length of the line and $\Delta_{0}$ is the phase difference between the microstrip line loaded with OCSRR and without OCSRR, $\lambda_{0}$ is the wavelength in free space and $\varepsilon_{\text {eff }}$ is the effective permittivity. The slow wave factor for the microstrip line with OCSRR and without OCSRR is shown in Fig. 8. From the figure, it is observed that the slow wave factor of microstrip line embedded with OCSRR is high when compared to the microstrip line without OCSRR. The increase in slow wave factor validates the size reduction capability of the OCSRR for microwave applications.

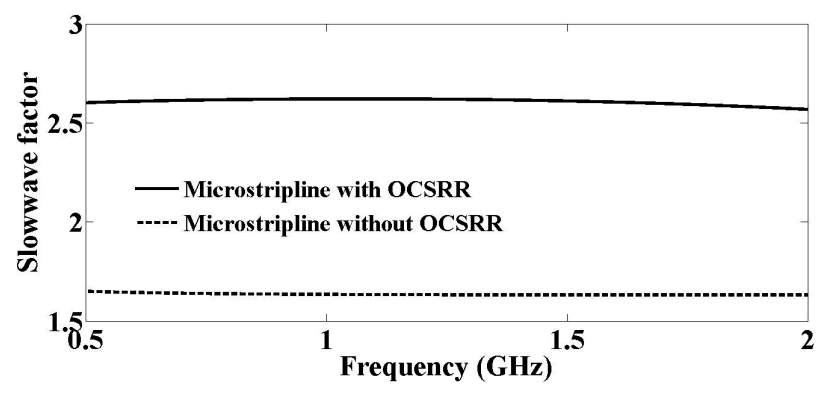

Fig. 8. Slow-wave factor of the microstrip line with and without OCSRR.

\section{Design of Power Divider using OCSRR}

To verify the size reduction capability of the OCSRR, a 1:4 unequal power divider is designed with a center frequency of $1.5 \mathrm{GHz}$. Figure 9 shows the schematic and simulated results of the conventional 1:4 lossless T-junction power divider.

To reduce the size of the power divider, the high impedance quarter wavelength transmission line is designed using OCSRR. When the conventional high impedance line is replaced by OCSRR embedded line, the OCSRR embedded microstrip line must have the same features as that of the conventional high impedance line i.e., it must have the same impedance $(111.8 \Omega)$ and it should offer a phase of $90^{\circ}$ at the design frequency. The simplified transmission line model to calculate the characteristic impedance of OCSRR embedded microstrip line is shown in Fig. 10.

The impedance of the OCSRR embedded microstrip line is calculated using the equations given in [1]

$$
S_{11}[\mathrm{~dB}]=20 \log |\Gamma|,
$$

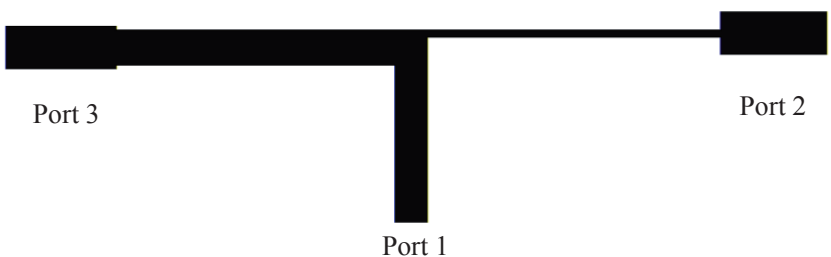

(a)

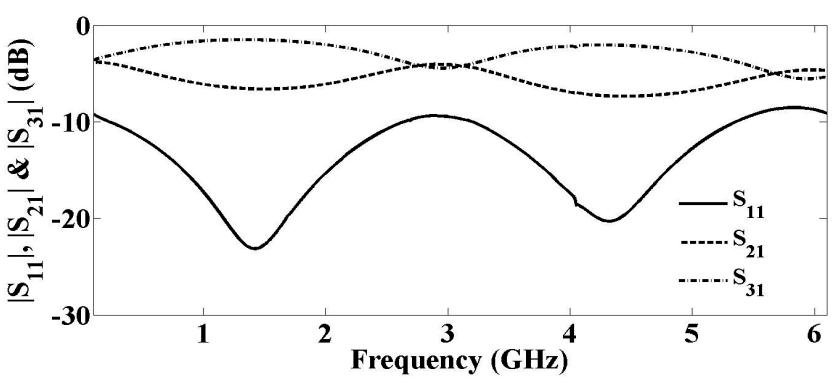

(b)

Fig. 9. Conventional unequal power divider: (a) Layout. (b) Scattering parameters.

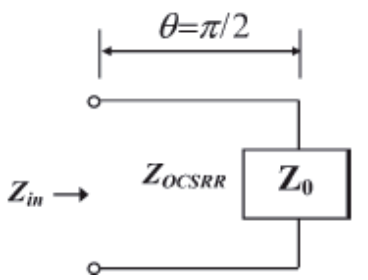

Fig. 10. Simplified transmission line model to determine the characteristic impedance of OCSRR embedded line.

$$
\begin{gathered}
Z_{\text {in }}=Z_{0} \frac{1+|\Gamma|}{1-|\Gamma|}, \\
Z_{\text {OCSRR }}=\sqrt{Z_{\text {in }} Z_{0}}=Z_{0} \sqrt{\frac{1+|\Gamma|}{1-|\Gamma|}} .
\end{gathered}
$$

To get $111.8 \Omega$ line impedance, the value of $\left|\mathrm{S}_{11}\right|$ should be $3.52 \mathrm{~dB}$ at the design frequency. In order to replace the conventional high impedance line with OCSRR embedded microstrip line, the OCSRR embedded microstrip line should have $\left|\mathrm{S}_{11}\right|=3.52 \mathrm{~dB}$ and phase of $\mathrm{S}_{21}=90^{\circ}$ at the design frequency. The dimensions of the OCSRR are optimized to obtain line impedance of $111.8 \Omega$ and required phase. The optimized dimensions of OCSRR are $a=5.22 \mathrm{~mm}, c=0.24 \mathrm{~mm}, d=0.24 \mathrm{~mm}, \quad g=0.3 \mathrm{~mm}$, $w=0.3 \mathrm{~mm}$ and the length of OCSRR embedded microstrip line is $12 \mathrm{~mm}$. The $55.9 \Omega$ quarter wavelength transmission line is also replaced with OCSRR embedded $50 \Omega$ microstrip line. To replace this low impedance line with OCSRR embedded microstrip line, the OCSRR embedded microstrip line must have $\left|S_{11}\right|=19 \mathrm{~dB}$ and phase of $S_{21}=90^{\circ}$ at the center frequency. The optimized dimensions of OCSRR for low impedance $55.9 \Omega$ line are $a=2.9 \mathrm{~mm}, \quad c=0.4 \mathrm{~mm}, \quad d=0.42 \mathrm{~mm}, \quad g=0.18 \mathrm{~mm}$, $w=0.3 \mathrm{~mm}$ and the length of OCSRR embedded microstrip line is $25 \mathrm{~mm}$. Fig. 11 shows the layout and fabricated prototype of 1:4 unequal power divider using OCSRR. The OCSRR embedded high impedance line is connected to port 2 and low impedance line is connected to port 3. 
Rohde \& Schwarz ZVL network analyzer is used for the testing of the fabricated prototype. Manual calibration is done before taking the measurement, it is calibrated in the plane of the SMA connector. The measurement set up is shown in Fig. 12. The simulated and measured scattering parameters of the proposed 1:4 unequal power divider is shown in Fig. 13. From Fig. 13(a) it is seen that power is unequally divided between the output ports. The insertion loss at port 2, $\left|S_{21}\right|$ is $6.94 \mathrm{~dB}$ and at port $3,\left|S_{31}\right|$ is $1.4 \mathrm{~dB}$, which are very close to ideal values $7 \mathrm{~dB}$ and $1 \mathrm{~dB}$. The return loss $\left|S_{11}\right|$ at the design frequency is $38 \mathrm{~dB}$. The isolation $\left|S_{23}\right|$ at $1.5 \mathrm{GHz}$ is $9.1 \mathrm{~dB}$. From the phase response it is observed that the two output port signals are in phase with each other at the design frequency.

Figure 14 shows the simulated and measured group delay of the proposed power divider. The group delay is greatly flat with a value of $0.25 \mathrm{~ns}$ at the operating frequency. The measured and simulated results are in good agreement. The performances of the proposed power divider are summarized in Tab. 1.

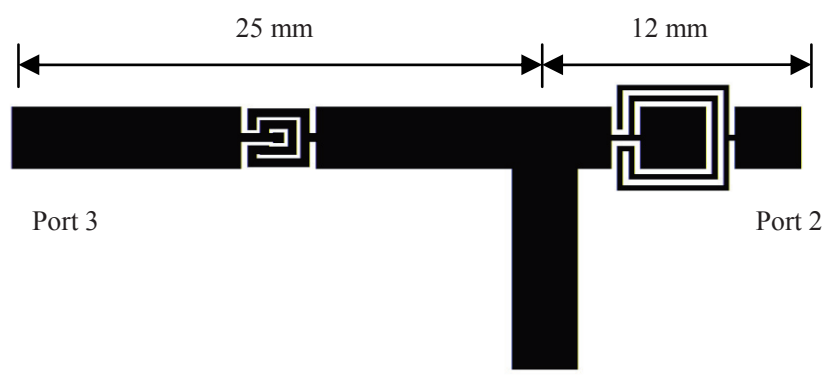

(a)

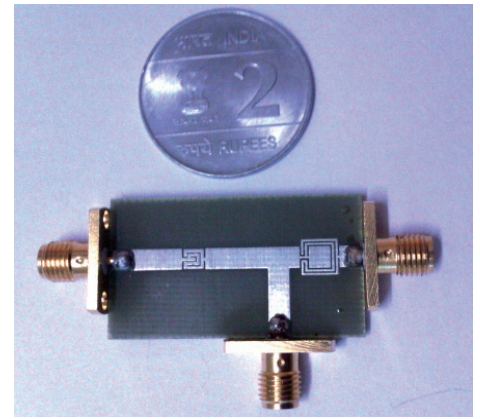

(b)

Fig. 11. Proposed 1:4 unequal power divider using OCSRR: (a) Layout. (b) Fabricated prototype.

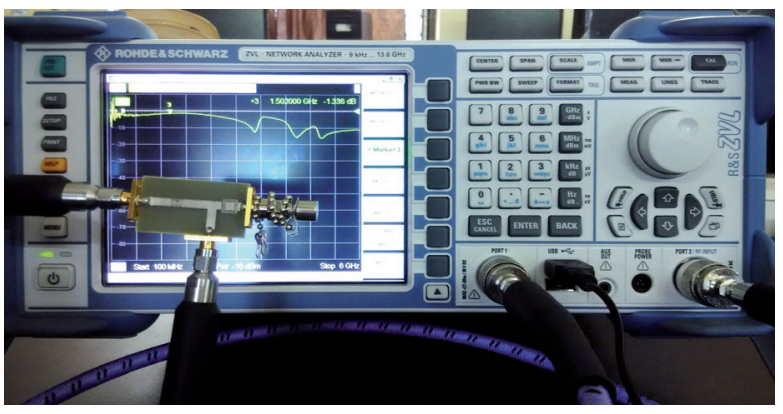

Fig. 12. Measurement setup.

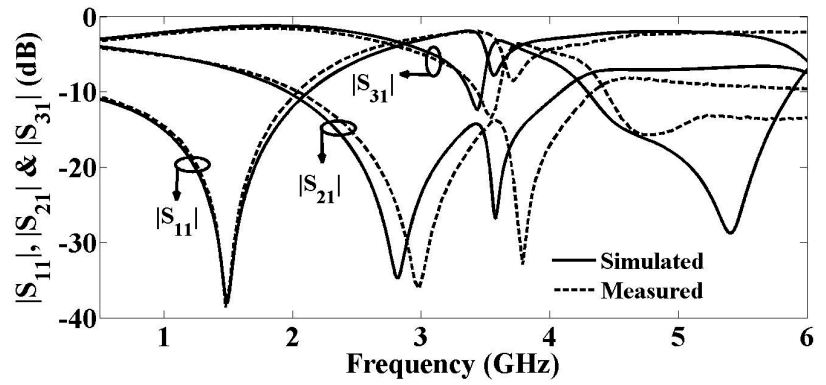

(a)

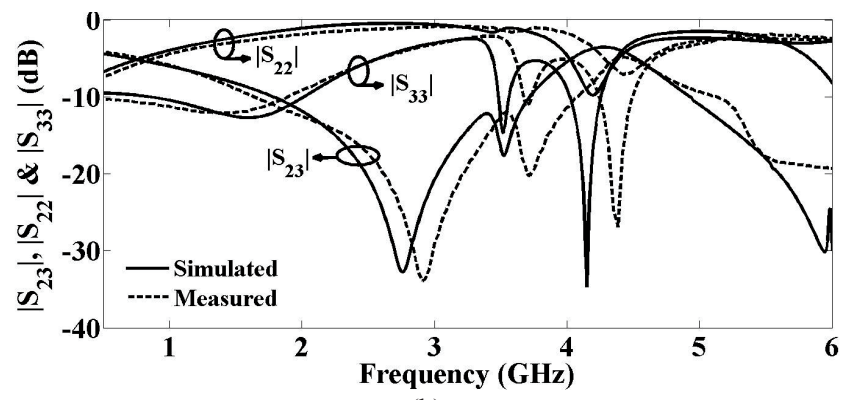

(b)

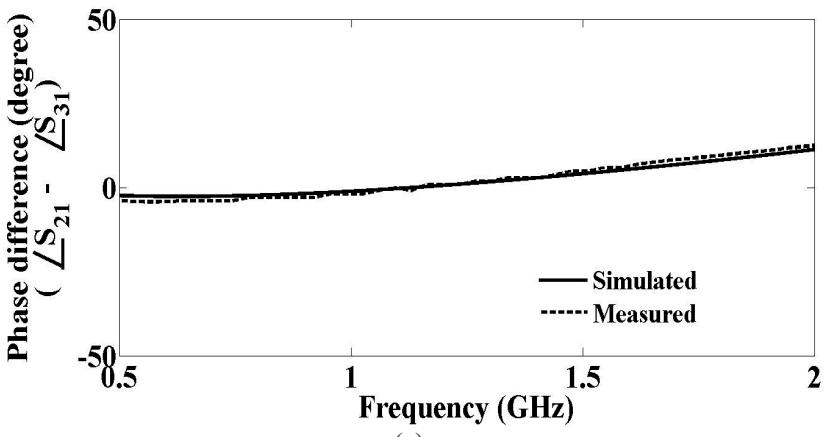

(c)

Fig. 13. Simulated and measured (a) magnitude response $\left(\left|S_{11}\right|\right.$, $\left.\left|\mathrm{S}_{21}\right| \&\left|\mathrm{~S}_{31}\right|\right)$, (b) magnitude response $\left(\left|\mathrm{S}_{23}\right|,\left|\mathrm{S}_{22}\right| \&\left|\mathrm{~S}_{33}\right|\right)$ and (c) phase difference between the output ports of the proposed 1:4 unequal power divider using OCSRR.

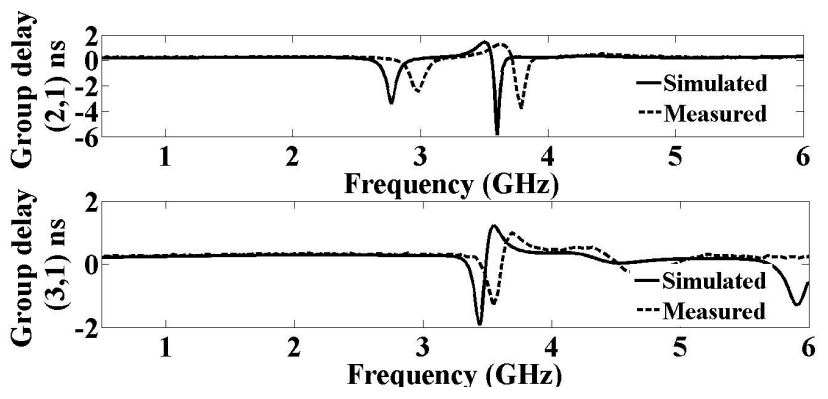

Fig. 14. Simulated and measured group delay of the proposed power divider.

From the magnitude response (Fig. 9(b)) of the conventional unequal power divider with an operating frequency of $1.5 \mathrm{GHz}$, it is observed that the response at $1.5 \mathrm{GHz}$ is repeating at $4.5 \mathrm{GHz}$ which is called harmonic. This is due to the distributed nature of the microstrip line. From the magnitude response of the proposed power divider (Fig. 13(a)) using OCSRR, it is observed that the harmonic is suppressed. This suppression is achieved due to the band stop characteristic of OCSRR. Table 2 gives the values of the scattering parameters at $4.5 \mathrm{GHz}$. 


\begin{tabular}{|c|c|c|}
\hline Parameter & Simulation & Measurement \\
\hline Operating frequency & $1.5 \mathrm{GHz}$ & $1.48 \mathrm{GHz}$ \\
\hline Return loss $\left|S_{11}\right|$ & $38.14 \mathrm{~dB}$ & $38.57 \mathrm{~dB}$ \\
\hline Output at port2 $\left|S_{21}\right|$ & $6.94 \mathrm{~dB}$ & $6.62 \mathrm{~dB}$ \\
\hline Output at port3 $\left|S_{31}\right|$ & $1.4 \mathrm{~dB}$ & $1.64 \mathrm{~dB}$ \\
\hline
\end{tabular}

Tab. 1. Performance of the proposed power divider.

\begin{tabular}{|c|c|c|}
\hline Parameter & Conventional & Proposed \\
\hline$\left|S_{11}\right|$ & $20 \mathrm{~dB}$ & $2.5 \mathrm{~dB}$ \\
\hline$\left|S_{21}\right|$ & $6.4 \mathrm{~dB}$ & $10.5 \mathrm{~dB}$ \\
\hline$\left|S_{31}\right|$ & $1.4 \mathrm{~dB}$ & $15 \mathrm{~dB}$ \\
\hline
\end{tabular}

Tab. 2. Scattering parameters at $4.5 \mathrm{GHz}$.

\section{Conclusion}

A lossless 1:4 unequal T-junction power divider using open complementary split ring resonator (OCSRR) is proposed in this paper. The length of high impedance quarter wavelength transmission line is reduced by $58.62 \%$. The proposed divider is very compact and the overall size is reduced by $51.94 \%$ when compared to the conventional $1: 4$ unequal power divider. Third harmonic suppression is also achieved. The simulated and measured results are in good agreement. Minor deviations from simulation and measurement results are due to fabrication tolerance and connector losses. The proposed divider validates the size reduction capability of OCSRR. The same technique can be used to design Wilkinson power divider, couplers etc.

\section{References}

[1] LIM, J.-S., LEE, S.-W., PARK, J.-S., AHN, D., NAM, S. A 4:1 unequal Wilkinson power divider. IEEE Microwave and Wireless Components Letters, 2001, vol. 11, p. 124-126. DOI: $10.1109 / 7260.915624$

[2] ORAIZI, H., ESFAHLAN, M. S. Miniaturization of Wilkinson power divider by using defected ground structures. Progress In Electromagnetics Research Letters, 2008, vol. 4, p. 113-120. DOI: 10.2528/PIERL08060701

[3] PACKIARAJ, D., BHARGAVI, A., RAMESH, M., KALGHATGI, A. T. Compact power divider using defected ground structure for wireless applications. In Proceedings of the IEEE International Conference on Signal Processing, Communications and Networking. Chennai (China), 2008, p. 25-29. DOI: 10.1109/ICSCN.2008.4447155

[4] SHUM, K. M., XUE, Q., CHAN, C. H. A Novel microstrip ring hybrid incorporating a PBG cell. IEEE Microwave and Wireless Components Letters, 2001, vol. 11, p. 258-260. DOI: $10.1109 / 7260.928931$

[5] LIN, C.-M., SU, H.-H., CHIU, J.-C., WANG, Y.-H. Wilkinson power divider using microstrip EBG cells for the suppression of harmonics. IEEE Microwave and Wireless Components Letters, 2007, vol. 17, p. 700-702. DOI: 10.1109/LMWC.2007.905595

[6] CHANG, C.-P., SU, C.-C., HUNG, S.-H., WANG, Y.-H. A 6:1 unequal Wilkinson power divider with EBG CPW. Progress In Electromagnetics Research Letters, 2009, vol. 8, p. 151-159. DOI: 10.2528/PIERL09032801
[7] SAENZ, E., CANTORA, A., EDERRA, I., GONZALO, R., DE MAAGT, P. A metamaterial T-junction power divider. IEEE Microwave Wireless Component Letters, 2007, vol. 17, p. 172-174. DOI: 10.1109/LMWC.2006.890447

[8] GARCIA-GARCIA, J., MARTIN, F., FALCONE, F., ET AL. Spurious passband suppression in microstrip coupled line bandpass filters by means of split ring resonators. IEEE Microwave Wireless Component Letters, 2004, vol. 14, p. 416-418. DOI: 10.1109/LMWC.2004.832066

[9] GARCIA-GARCIA, J., MARTIN, F., FALCONE, F., ET AL. Microwave filters with improved stopband based on sub-wavelength resonators. IEEE Transaction Microwave Theory Technology, 2005, vol. 53, p. 1997-2006. DOI: 10.1109/TMTT.2005.848828

[10] KARTHIKEYAN, S. S., KSHETRIMAYUM, R. S. Performance enhancement of microstrip bandpass filter using CSSRR. In International Conference on Advances in Computing, Control and Telecommunication Technologies ACT. Trivandrum (India), 2009, p. 67-70. DOI: $10.1109 / \mathrm{ACT} .2009 .27$

[11] ZHANG, J., CUI, B., GU, J.-Z., SUN, X.-W. A harmonic suppressed Wilkinson power divider using complementary split ring resonator. Journal of Electromagnetic Waves and Application, 2007, vol. 21, p. 811-819. DOI: $10.1163 / 156939307780749165$

[12] AZNAR-BALleSta, F., GARCIA-PEREZ, O., GONZALEZPOSADAS, V., SEGOVIA-VARGAS, D. Recursive active filter with metamaterial unequal Wilkinson power dividers. In European Microwave Conference. Paris (France), 2010, p. 930-933. ISBN: 9781424472321

[13] VEleZ, A., AZNAR, F., BONACHE, J., ET AL. Open complementary split ring resonators (OCSRRs) and their application to wideband CPW bandpass filters. IEEE Microwave Wireless Component Letters, 2009, vol. 19, no. 4, p. 197-199. DOI: 10.1109/LMWC.2009.2015490

[14] AZNAR, F., VELEZ, A., BONACHE, J., ET AL. Compact low pass filter with very sharp transition bands based on open complementary split ring resonator. Electronics Letters, 2009, vol. 45 , no. 6 , p. $316-317$. DOI: $10.1049 /$ el.2009.2854

[15] AZNAR, F., VELEZ, A., DURAN-SINDREU, M., ET AL. Elliptic-function CPW low pass filters implemented by means of open complementary split ring resonators (OCSRRs). IEEE Microwave Wireless Component Letters, 2009, vol. 19, no. 11, p. 689-691. DOI: 10.1109/LMWC.2009.2032000

[16] KARTHIKEYAN, S. S., KSHETRIMAYUM, R. S. Compact, deep and wide rejection bandwidth low-pass filter using open complementary split ring resonator. Microwave and Optical Technology Letters, 2011, vol. 53, no. 4, p. 845-848. DOI: 10.1002/mop.25874

[17] LIU, J. X., YIN, W. Y., HE, S. L. A new defected ground structure and its applications for miniaturized switchable antenna. Progress in Electromagnetic Research, 2010, vol. 107, p. 115-128. DOI: 10.2528/PIER10050904

\section{About the Authors ...}

V. PHANI KUMAR KANAPARTHI was born in Andhra Pradesh, India. He received the B. Tech degree in Electronics and Communication Engineering from Acharya Nagarjuna University, Guntur, India in 2010 and the M. Des degree in Electronic System from Indian Inst. of Information Technology Design and Manufacturing, Kancheepuram, India in 2013. His research interests include microwave passive circuits and RFIC.

S. S. KARTHIKEYAN - for CV see p. 711 of this issue. 